\title{
Transversus abdominis plane block for analgesia after Cesarean delivery: a systematic review and meta-analysis
}

\section{Bloc dans le plan du muscle transverse de l'abdomen après accouchement par césarienne: revue systématique de la littérature et méta-analyse}

\author{
Basem M. Mishriky, MD • Ronald B. George, MD • \\ Ashraf S. Habib, MBBCh \\ Received: 20 February 2012 / Accepted: 1 May 2012/Published online: 24 May 2012 \\ (C) Canadian Anesthesiologists' Society 2012
}

\begin{abstract}
Purpose To assess the efficacy of transversus abdominis plane (TAP) block in improving analgesia following Cesarean delivery $(C D)$.

Source We searched MEDLINE, CENTRAL, EMBASE, and CINAHL for randomized controlled trials that assessed the efficacy of TAP block following CD and reported on postoperative pain scores and/or opioid consumption. Studies were combined according to the use or non-use of intrathecal morphine (ITM). Another analysis was performed for studies comparing TAP block with ITM.

Principal findings Nine studies were included. Transversus abdominis plane block significantly reduced opioid consumption (mg morphine equivalents) after Cesarean delivery at six hours (mean difference [MD] -10.18; 95\% confidence interval [CI] -13.03 to -7.34$)$, at $12 \mathrm{hr}(\mathrm{MD}$ -13.83; 95\% CI -22.77 to -4.89), and at $24 \mathrm{hr}$ (MD -20.23 ; $95 \%$ CI -33.69 to -6.77$)$. The TAP block also reduced pain scores for up to $12 \mathrm{hr}$ and nausea in patients who did not receive ITM. When added to ITM, TAP block produced a small reduction in pain scores on movement in
\end{abstract}

Author contributions Ashraf S. Habib was responsible for the concept and design of the study and he critically revised the manuscript. Ashraf S. Habib, Basem M. Mishriky, and Ronald B. George were involved in conducting the study, extracting data, and manuscript preparation. Basem M. Mishriky and Ronald B. George analyzed the data.

B. M. Mishriky, MD · A. S. Habib, MBBCh $(\varangle)$

Department of Anesthesiology, Duke University Medical Center,

Box 3094, Durham, NC 27710, USA

e-mail: habib001@dm.duke.edu

R. B. George, MD

Department of Anesthesiology, Dalhousie University IWK

Health Centre, Halifax, NS, Canada the first six hours (MD-0.82, 95\% CI - 1.52 to -0.11). When compared with ITM, pain scores on movement and opioid consumption at $24 \mathrm{hr}$ were lower (MD 0.98; $95 \% \mathrm{CI}$ 0.06 to 1.91 and MD $8.42 \mathrm{mg}$; $95 \% \mathrm{CI} 1.74$ to 15.10 , respectively), and time to first rescue analgesic was longer with ITM ( $8 \mathrm{hr}$ vs $4 \mathrm{hr}$ ), although opioid-related side effects were more common.

Conclusion Transversus abdominis plane block significantly improved postoperative analgesia in women undergoing $C D$ who did not receive ITM but showed no improvement in those who received ITM. Intrathecal morphine was associated with improved analgesia compared with TAP block alone at the expense of an increased incidence of side effects.

\section{Résumé}

Objectif Évaluer l'efficacité du bloc dans le plan $d u$ muscle transverse de l'abdomen (TAP) pour l'amélioration de l'analgésie après accouchement par césarienne.

Source Nous avons recherché des essais randomisés contrôlés qui évaluaient l'efficacité du bloc TAP et qui présentaient des scores de douleur postopératoire et/ou de consommation de morphiniques dans les bases de données MEDLINE, CENTRAL, EMBASE et CINAHL. Les études ont été combinées en fonction de l'utilisation, ou non, de morphine intrathécale. Une autre analyse a été réalisée pour les études comparant le bloc TAP à l'utilisation de morphine intrathécale.

Constatations principales Neuf études ont été incluses. Le bloc dans le plan du muscle transverse de l'abdomen a réduit de façon significative la consommation de morphiniques (en mg d'équivalents morphine) six heures après (différence moyenne [DM]: -10,18; intervalle de confiance à $95 \%$ [IC]: $-13,03$ à-7,34), $12 \mathrm{~h}$ après (DM: $-13,83 ;$ IC à 
$95 \%:-22,77$ à $-4,89)$ et 24 h après une césarienne (DM: -20,23; IC à 95\%: -33,69 à-6,77). Le bloc TAP a également réduit les scores de douleur pendant une période pouvant atteindre 12 heures et les nausées chez les patientes n'ayant pas reçu de morphinique intrathécal. Ajouté à la morphine intrathécale, le bloc TAP a entrainé une petite diminution des scores de douleur sur le mouvement au cours des six premières heures (DM: -0,82, IC à $95 \%$ : -1,52 à-0,11). Comparativement à la morphine intrathécale, les scores de douleurs au mouvement et la consommation de morphiniques à 24 hont été plus faibles (respectivement, DM: 0,98; IC $95 \%$ : 0,06 à 1,91 et DM: 8,42 mg; IC à $95 \%: 1,74$ à 15,10), et le temps écoulé jusqu'au premier analgésique de secours a été plus long avec la morphine intrathécale $(8 \mathrm{~h}$ contre $4 \mathrm{~h})$ bien que les effets indésirables liés au morphinique aient étéplus fréquents.

Conclusion Le bloc dans le plan du muscle transverse de l'abdomen a amélioré l'analgésie postopératoire chez des femmes subissant une césarienne qui n'avaient pas reçu de morphine intrathécale, mais n'a pas entrainé d'amélioration chez celles qui en avaient reçu. La morphinique intrathécale a été associée à une meilleure analgésie que le bloc TAP seul, mais avec une augmentation de l'incidence des effets indésirables.

Achieving ideal pain control following Cesarean delivery (CD) remains a challenge. Inadequate postoperative analgesia is one of the most common causes for poor patient satisfaction following CD. ${ }^{1}$ It may delay ambulation predisposing to thromboembolic events ${ }^{1,2}$ and may impact early bonding with the newborn. ${ }^{3}$ Neuraxial opioids are commonly used for postoperative analgesia; however, their use is associated with a high incidence of adverse effects, such as postoperative nausea and vomiting and pruritus. ${ }^{4}$ Consequently, other therapies are needed to replace or reduce opioid use and therefore decrease opioid-related side effects. ${ }^{1}$

Transversus abdominis plane (TAP) block is a regional anesthetic technique that blocks T6-L1 nerve roots and can provide analgesia for lower abdominal procedures. ${ }^{5}$ It can be performed using anatomic landmarks or under ultrasound (US) guidance. ${ }^{5,6}$ Previous meta-analyses of this technique, including patients undergoing a variety of surgeries under general or neuraxial anesthesia, showed that TAP block improves pain control and reduces opioid consumption as well as opioid-related side effects. ${ }^{7-9}$ We performed this systematic review and meta-analysis to assess the efficacy of TAP block in decreasing postoperative pain scores and opioid consumption in parturients undergoing $\mathrm{CD}$.

\section{Methods}

We followed the recommendations of the PRISMA statement. $^{10}$ We searched MEDLINE (1966-2012), the Cochrane Central Register of Controlled Trials (CENTRAL), EMBASE (1947-2012), and CINAHL for randomized controlled trials (RCTs) that assessed the efficacy of TAP block in women undergoing $\mathrm{CD}$ and reported on postoperative pain intensity scores and/or opioid consumption. The term "transversus abdominis plane block" was searched and combined with the term "cesarean section". The search was performed without limits or language restriction. The date of the last computer search was March 2012. In addition, the bibliographies of retrieved articles were searched for additional studies. Reviews, abstracts, letters to the editor, and retrospective studies were excluded.

The selected articles meeting the inclusion criteria were assessed separately by two reviewers (B.M. and R.G.) using the risk of bias table suggested by the Cochrane Collaboration ${ }^{11}$ evaluating selection bias (randomization sequence generation and allocation concealment), performance bias (blinding of participants and personnel), detection bias (blinding to outcome assessment), attrition bias (incomplete outcome data), and reporting bias (selective reporting). For each parameter, studies were assessed as low, unclear, or high risk of bias. Any discrepancies were resolved by discussion with the third reviewer (A.H.).

A data collection sheet was created and two reviewers (B.M., R.G.) extracted data independently on: 1) anesthesia technique, 2) TAP block technique (landmark or US-guided technique) and local anesthetic used, 3) number of patients included, 4) primary outcome of the study, 5) postoperative analgesia regimen, 6) pain intensity scores at rest and on movement, 7) opioid consumption, 8) time to first analgesic, 9) side effects (nausea, vomiting, need for rescue antiemetics, pruritus, and sedation), 10) persistent pain, and 11) patient satisfaction. If any data were reported in a graph, the authors were contacted, and if the authors did not respond, the reviewers extracted the data from the graph. Any discrepancies in extracted data were resolved by discussion with the third reviewer (A.H.).

The primary outcomes were pain intensity scores and opioid consumption at $24 \mathrm{hr}$. Secondary outcomes were pain intensity scores at six, 12 , and $48 \mathrm{hr}$, opioid consumption at the same time points, time to first analgesia, side effects, and patient satisfaction.

When TAP block was compared with inactive control, studies were combined according to use or non-use of intrathecal morphine (ITM). Another analysis was performed for studies comparing TAP block with ITM. Visual analogue scale (VAS) scores for pain intensity and patient 
satisfaction reported on a $0-100$ scale were converted to a 0-10 point scale for analysis. If both somatic and visceral pain were reported, the higher pain score was used. If results were not reported at the time points specified in this analysis, those recorded close to that time point were used instead. Tramadol consumption was converted to morphine equivalents using a conversion factor of $1: 10 .^{12}$ If sedation was not reported, drowsiness results were used to indicate sedation. If an event rate was reported over multiple time intervals instead of the entire duration of the study, the highest recorded incidence over the duration of the study was used in the analysis.

Continuous data were summarized as mean difference (MD) with $95 \%$ confidence interval (CI). If the $95 \%$ CI included a value of 0 , we considered the difference between TAP block and control not statistically significant. Dichotomous data were summarized as relative risk (RR) with $95 \%$ CI. If the $95 \%$ CI included a value of 1 , we considered the difference between TAP block and control not statistically significant. Analyses were performed using the Review Manager (RevMan) version 5.1 (Copenhagen: The Nordic Cochrane Centre, The Cochrane Collaboration, 2011). A random effects model was used. We considered heterogeneity to be present if the $\mathrm{I}^{2}$ test was $>50 \%$. Forest plots were used to represent and evaluate treatment effects graphically. A subgroup analysis was performed using the
$\mathrm{Q}$ test for the primary end points according to completion of the TAP block using the anatomical landmark or the USguided technique.

\section{Results}

Eighty-six studies were initially identified, and 77 of those studies were excluded (Fig. 1). Nine studies with 524 patients were included in the final analysis; ${ }^{13-21} 261$ patients received TAP block and 263 served as controls. The characteristics of the included studies are shown in Table 1, and the risk of bias of the included studies is shown in Table 2.

Seven studies were performed under spinal anesthesia $^{13-18,21}$ and two were performed under general anesthesia. $^{19,20}$ Transversus abdominis plane block was performed in all studies at the end of the CD using the anatomical landmark technique in three studies ${ }^{17,18,20}$ and the US-guided technique in six studies. ${ }^{13-16,19,21}$ In six studies, TAP block and control groups were compared and did not receive ITM (four under spinal anesthesia ${ }^{13,14,17,18}$ with intrathecal fentanyl alone in doses ranging from 10-25 $\mu \mathrm{g}$ and two under general anesthesia). ${ }^{19,20}$ In two studies, TAP block and control groups were compared with all patients receiving ITM $100 \mu \mathrm{g}$ added to fentanyl
Fig. 1 Flow diagram for literature search

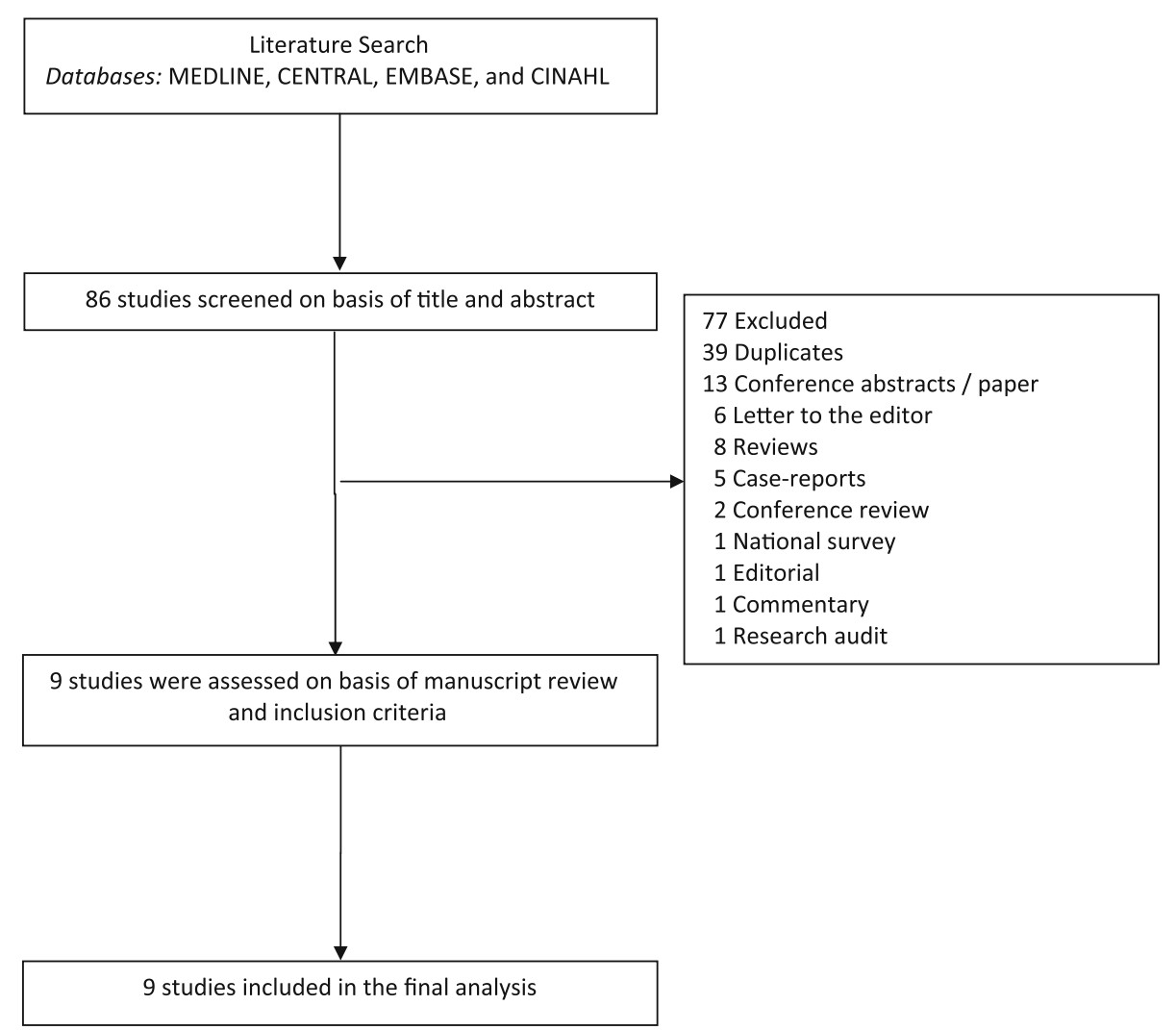




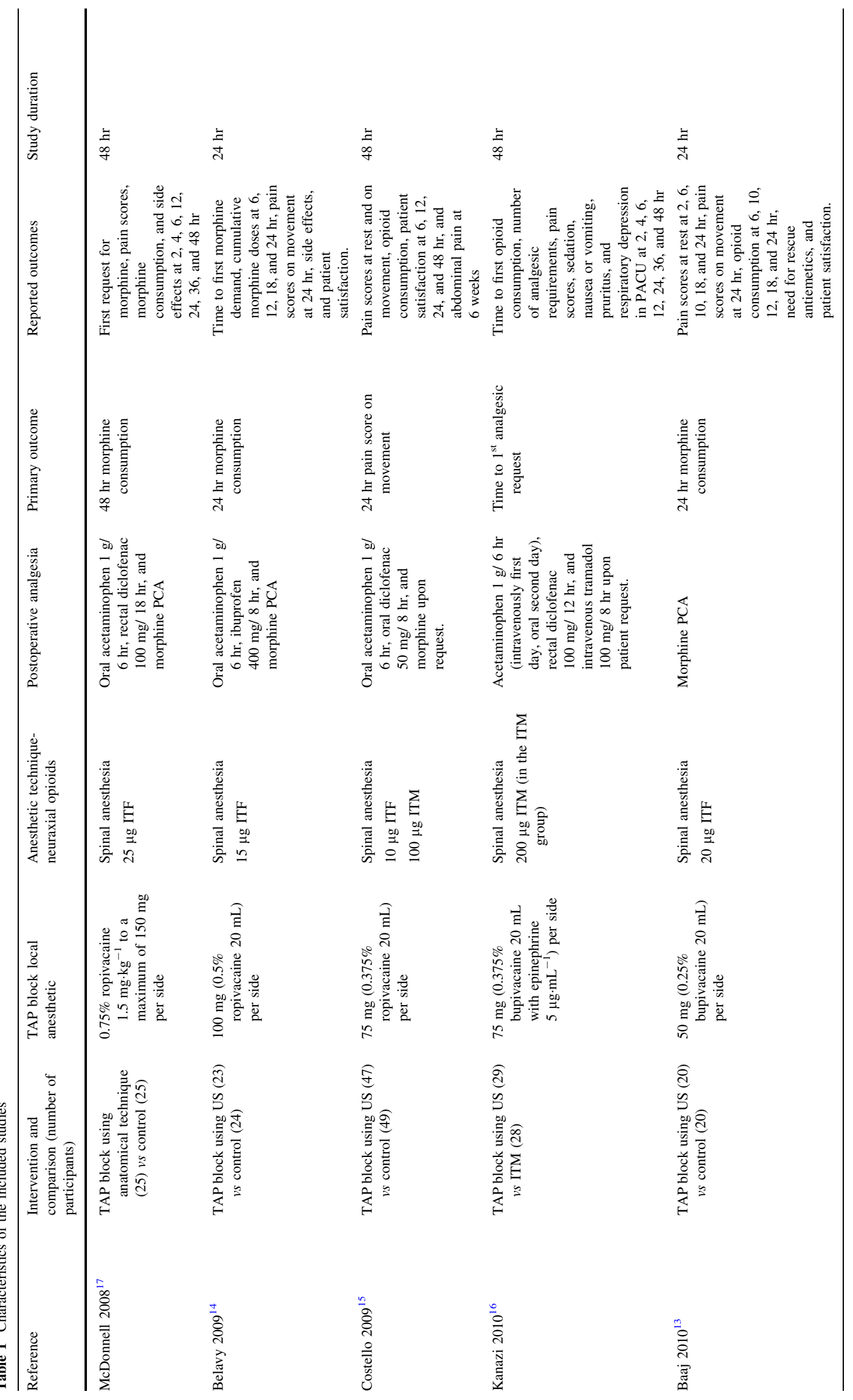




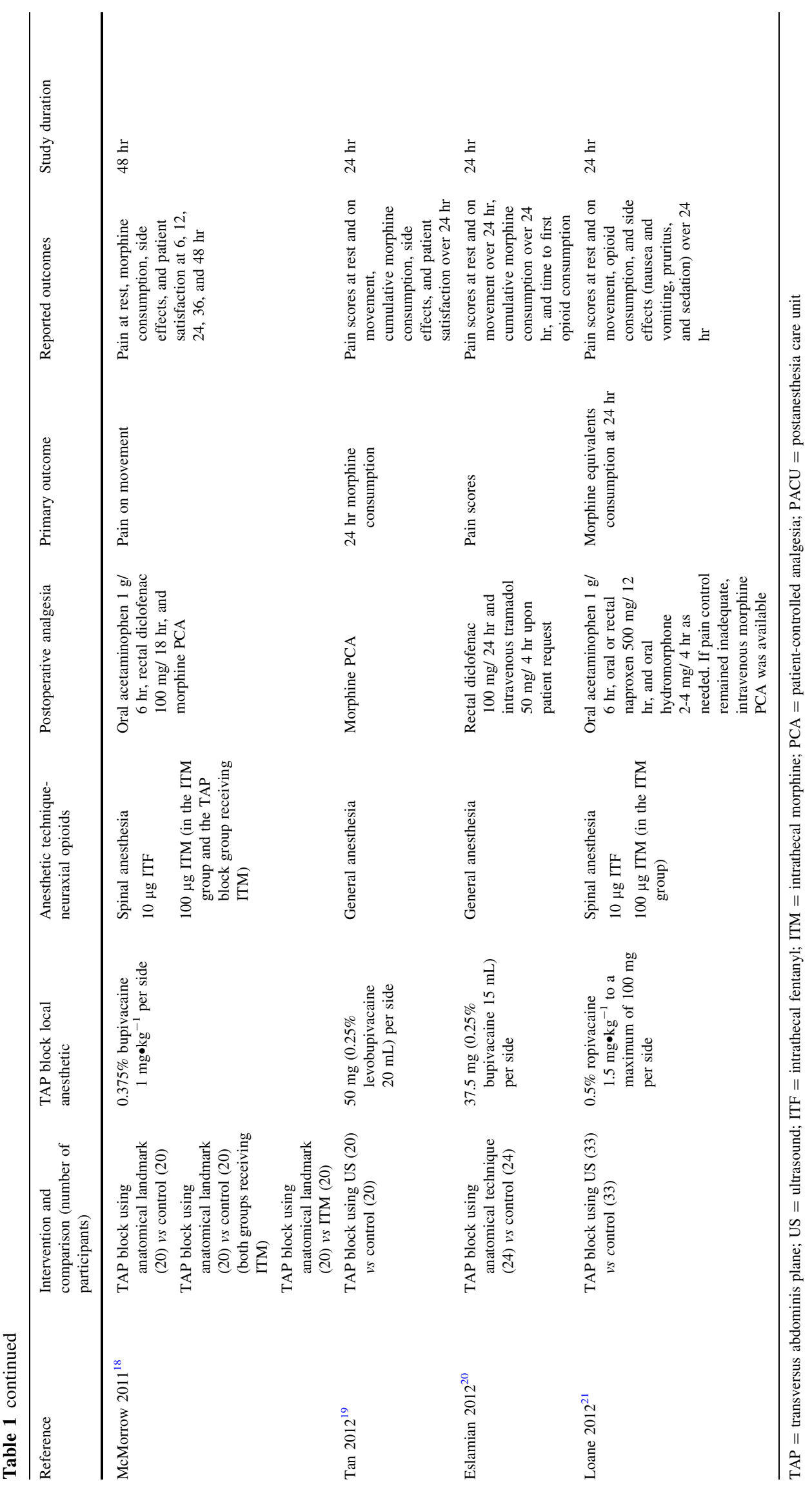


Table 2 The risk of bias table of the included studies

\begin{tabular}{|c|c|c|c|c|c|c|}
\hline Reference & $\begin{array}{l}\text { Randomization sequence } \\
\text { generation }\end{array}$ & $\begin{array}{l}\text { Allocation } \\
\text { concealment }\end{array}$ & $\begin{array}{l}\text { Blinding of participants } \\
\text { and personnel }\end{array}$ & $\begin{array}{l}\text { Blinding of outcome } \\
\text { assessment }\end{array}$ & $\begin{array}{l}\text { Incomplete } \\
\text { outcome data }\end{array}$ & $\begin{array}{l}\text { Selective } \\
\text { reporting }\end{array}$ \\
\hline $\begin{array}{l}\text { McDonnell } \\
2008^{17}\end{array}$ & Low & Low & Low & Low & Low & Low \\
\hline $\begin{array}{l}\text { Belavy } \\
2009^{14}\end{array}$ & Low & Low & Low & Unclear & Low & Low \\
\hline $\begin{array}{l}\text { Costello } \\
2009^{15}\end{array}$ & Low & Unclear & Low & Low & Low & Low \\
\hline $\begin{array}{l}\text { Kanazi } \\
2010^{16}\end{array}$ & Low & Low & Low & Low & Low & Low \\
\hline Baaj $2010^{13}$ & Unclear & Unclear & Low & Unclear & Low & Low \\
\hline $\begin{array}{l}\text { McMorrow } \\
2011^{18}\end{array}$ & Low & Low & Low & Unclear & Low & Low \\
\hline Tan $2012^{19}$ & Low & Low & Low & Low & Low & Low \\
\hline $\begin{array}{r}\text { Eslamian } \\
2012^{20}\end{array}$ & Low & Unclear & Low & Low & Low & Low \\
\hline $\begin{array}{l}\text { Loane } \\
\qquad 2012^{21}\end{array}$ & Low & Low & Low & Low & Low & Low \\
\hline
\end{tabular}

Low $=$ low risk of bias; Unclear $=$ unclear risk of bias

$10 \mu \mathrm{g},{ }^{15,18}$ and in three studies, ${ }^{16,18,21}$ TAP block groups were compared with ITM $100 \mu \mathrm{g}^{18,21}$ and $200 \mu \mathrm{g}$ groups. ${ }^{16}$ The TAP block local anesthetic was ropivacaine in four studies, ${ }^{14,15,17,21}$ bupivacaine in four studies, ${ }^{13,16,18,20}$ and levobupivacaine in one study. ${ }^{19}$

In two studies, the postoperative analgesia regimen was provided using patient-controlled analgesia (PCA) with morphine. ${ }^{13,19}$ In one study, a combination of nonsteroidal anti-inflammatory drugs (NSAIDs) and intravenous opioids was provided, ${ }^{20}$ and in the remaining studies, a combination of acetaminophen, NSAIDs, and opioids (orally or as intravenous PCA) was provided. ${ }^{14-18,21}$

TAP block vs control in patients who did not receive ITM

In six studies, ${ }^{13,14,17-20}$ TAP block was compared with control in patients who did not receive ITM. Spinal anesthesia was used in four studies ${ }^{13,14,17,18}$ while two used general anesthesia. ${ }^{19,20}$ Spinal anesthesia was performed with hyperbaric bupivacaine and fentanyl 10-25 $\mu \mathrm{g}$ administered to all patients. In four studies, ${ }^{13,14,17,18}$ TAP block with either ropivacaine or bupivacaine was compared with TAP block with saline, while in two studies, ${ }^{19,20}$ TAP block with bupivacaine or levobupivacaine was compared with control with no block. In three studies, ${ }^{17,18,20}$ TAP block was performed using anatomical landmarks, while in three studies, ${ }^{13,14,19}$ the US-guided technique was used.

\section{Pain intensity scores at $24 \mathrm{hr}$}

Pain scores at $24 \mathrm{hr}$ at rest and on movement were investigated in five $\mathrm{e}^{13,17-20}$ and $\operatorname{six}^{13,14,17-20}$ studies, respectively, with only one study reporting a statistically significant reduction with the TAP block. ${ }^{13}$ Pooled results showed no difference between the two groups either at rest (MD $0.32 ; 95 \% \mathrm{CI}-1.18$ to $0.54 ; \mathrm{I}^{2}=87 \%$ ) or on movement (MD $-1.65 ; 95 \% \mathrm{CI}-3.42$ to $0.12 ; \mathrm{I}^{2}=95 \%$ ) (Fig. 2 ).

\section{Opioid consumption at $24 \mathrm{hr}$}

Opioid consumption at $24 \mathrm{hr}$ was investigated in six studies, ${ }^{13,14,17-20}$ with five studies ${ }^{13,14,17,19,20}$ reporting a statistically significant reduction in opioid consumption in the TAP block group. In the sixth study, ${ }^{18} 24-\mathrm{hr}$ opioid consumption was numerically higher in the TAP block group, but the differences were not statistically significant. Pooled results (Fig. 3) showed a statistically significant lower opioid consumption at $24 \mathrm{hr}$ in the TAP block group (MD $-20.23 \mathrm{mg}$ morphine equivalents; 95\% CI -33.69 to $\left.-6.77 ; \mathrm{I}^{2}=97 \%\right)$.

Pain intensity scores at six, 12, and $48 \mathrm{hr}$

Pain scores at six, 12 , and $48 \mathrm{hr}$ at rest were investigated in five, ${ }^{13,17-20}$ four, ${ }^{13,17,19,20}$ and two ${ }^{17,18}$ studies, respectively, and pain scores on movement were investigated in four, ${ }^{17-20}$ three, ${ }^{17,19,20}$ and two ${ }^{17,18}$ studies, respectively. Pooled results showed a statistically significant reduction 


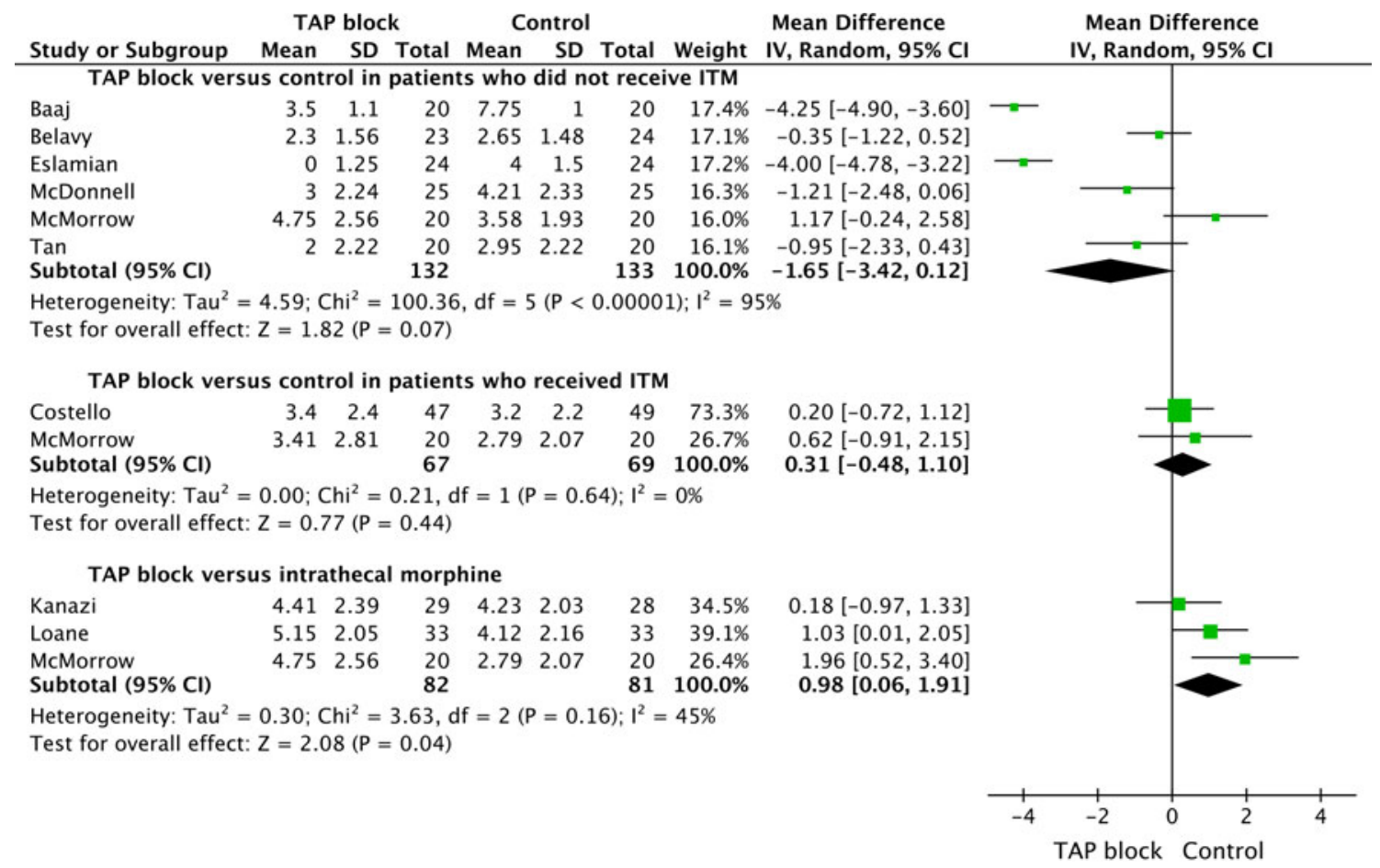

Fig. 2 Pain scores on movement at $24 \mathrm{hr}$. TAP $=$ transversus abdominis plane; ITM = intrathecal morphine; CI = confidence interval

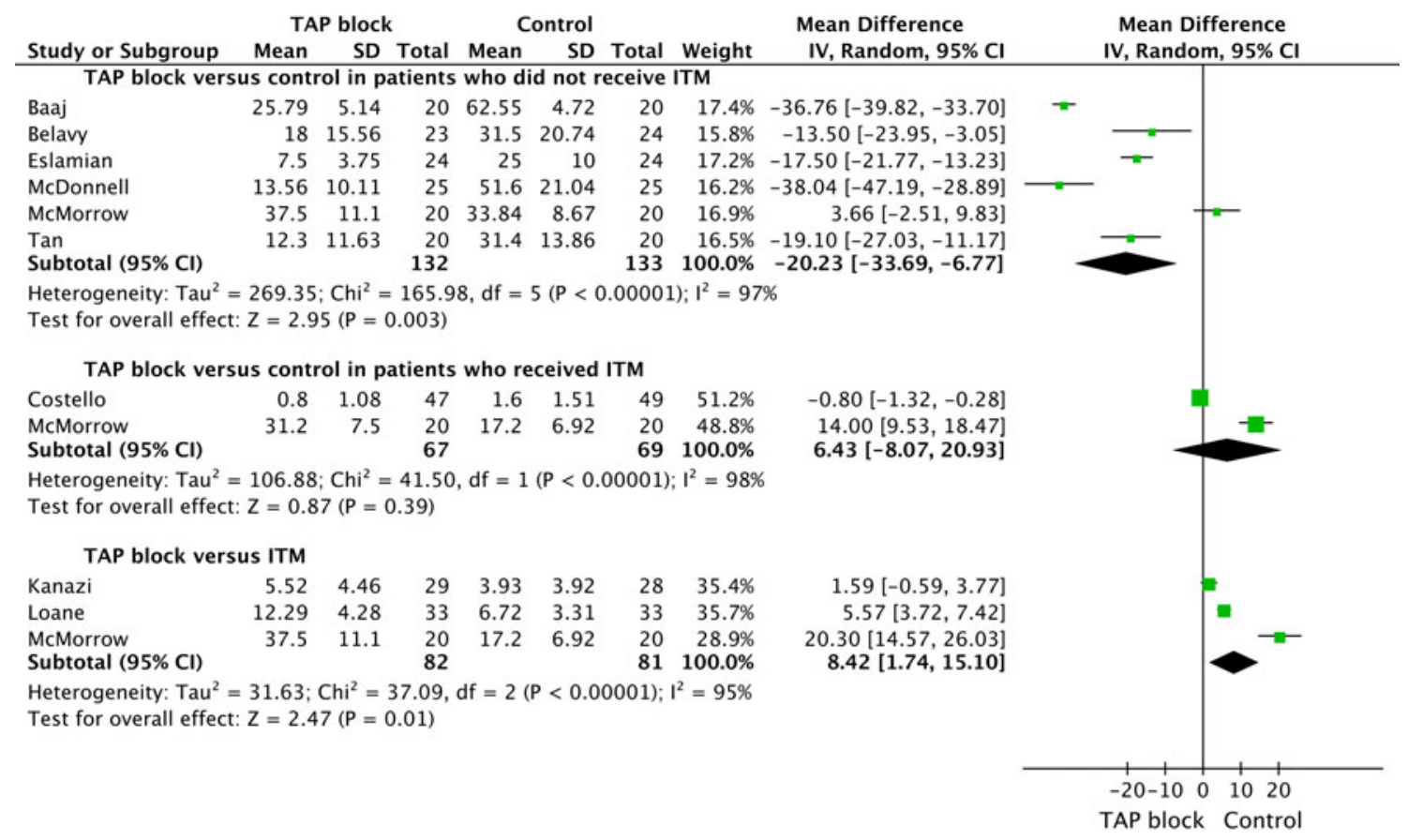

Fig. 3 Opioid consumption at $24 \mathrm{hr}$. TAP $=$ transversus abdominis plane; ITM $=$ intrathecal morphine; $\mathrm{CI}=$ confidence interval

in pain scores at rest at six hours (MD $-1.61 ; 95 \% \mathrm{CI}$ -3.17 to $\left.-0.05 ; \mathrm{I}^{2}=97 \%\right)$ and at rest at $12 \mathrm{hr}(\mathrm{MD}$ $-1.49 ; 95 \% \mathrm{CI}-2.24$ to $-0.73 ; \mathrm{I}^{2}=83 \%$ ) but not at $48 \mathrm{hr}$ with TAP block (MD 0.19; 95\% CI -0.84 to 1.22 ; $\mathrm{I}^{2}=69 \%$ ). Similarly, pooled results for pain scores on movement showed a statistically significant reduction with TAP block at six hours (MD $-2.21 ; 95 \% \mathrm{CI}-4.03$ to $\left.-0.40 ; \mathrm{I}^{2}=90 \%\right)$ and at $12 \mathrm{hr}(\mathrm{MD}-1.73 ; 95 \% \mathrm{CI}-2.47$ to $-0.98 ; \mathrm{I}^{2}=19 \%$ ) but not at $48 \mathrm{hr}$ (MD $-0.41 ; 95 \%$ CI -2.30 to $1.47 ; \mathrm{I}^{2}=78 \%$ ). 
Opioid consumption at six, 12, and $48 \mathrm{hr}$

Opioid consumption at six, 12 , and $48 \mathrm{hr}$ was investigated in five, ${ }^{13,14,17-19}$ five, ${ }^{13,14,17-19}$ and two ${ }^{17,18}$ studies, respectively. Pooled results showed a statistically significant reduction in opioid consumption at six hours (MD $10.18 \mathrm{mg}$ morphine equivalents; $95 \% \mathrm{CI}-13.03$ to -7.34 ; $\left.\mathrm{I}^{2}=67 \%\right)$ and at $12 \mathrm{hr}$ (MD $-13.83 \mathrm{mg}$ morphine equivalents; $95 \%$ CI -22.77 to $-4.89 ; \mathrm{I}^{2}=94 \%$ ). No conclusion can be made for the opioid consumption at 48 $\mathrm{hr}$ due to the wide confidence interval (MD $-18.02 \mathrm{mg}$ morphine equivalents; $95 \%$ CI -76.12 to 40.08 ; $\mathrm{I}^{2}=99 \%$ ).

\section{Time to first analgesia}

Time to first analgesia was investigated in three studies, ${ }^{14,17,20}$ with the pooled results showing a statistically significant prolongation in the TAP block group (MD 2.43 hr; $95 \%$ CI 0.55 to $4.31 ; \mathrm{I}^{2}=91 \%$ ).

\section{Side effects}

Side effects are presented in Table 3. Transversus abdominis plane block caused a statistically significant reduction in the incidence of nausea (RR 0.54 ; 95\% CI 0.30 to $0.97 ; \mathrm{I}^{2}=0 \%$ ); however, no difference was found in the incidence of vomiting, need for rescue antiemetics, pruritus, or sedation.

\section{Patient satisfaction}

Patient satisfaction at $24 \mathrm{hr}$ was reported in four studies. $^{13,14,18,19}$ A VAS score was used in two studies, ${ }^{14,18}$ with one study ${ }^{14}$ reporting a significantly higher satisfaction in the TAP block group. Pooled results from the two studies showed no difference between the two groups (MD $1.12 ; 95 \% \mathrm{CI}-0.71$ to $2.95 ; \mathrm{I}^{2}=72 \%$ ). In the remaining two studies, ${ }^{13,19}$ one $^{13}$ reported patient satisfaction as being either good or acceptable, while the other ${ }^{19}$ reported patients being very dissatisfied, dissatisfied, satisfied, or very satisfied. Pooling the good and very satisfied results showed a statistically significant higher patient satisfaction with the TAP block (RR 2.12; 95\% CI 1.06 to 4.24; $\mathrm{I}^{2}=60 \%$ ).

\section{Subgroup analysis}

Comparing the two techniques of performing the TAP block (anatomical landmark $v s$ US-guided) did not reveal any differences between the two techniques in pain scores on movement or analgesic consumption at $24 \mathrm{hr}$; however, there was a significant difference in pain scores at rest at 24 $\mathrm{hr}$ in favour of the US-guided technique $(P=0.02)$.

TAP block vs control in patients who received ITM

In two studies, ${ }^{15,18}$ TAP block was compared with control in all patients receiving ITM. Spinal anesthesia was performed with hyperbaric bupivacaine using a combination of fentanyl $10 \mu \mathrm{g}$ and morphine $100 \mu \mathrm{g}$. In the two studies, TAP block with bupivacaine or ropivacaine was compared with TAP block with saline. In one study, ${ }^{18}$ TAP block was performed using the anatomical landmarks, while in the other, ${ }^{15}$ the US-guided technique was used.

\section{Pain intensity scores at $24 \mathrm{hr}$}

Pain scores at $24 \mathrm{hr}$ at rest and on movement were investigated in the two studies ${ }^{15,18}$ with both studies reporting no difference between the two groups. Pooled results showed no difference between the groups either at rest (MD 0.22; $95 \% \mathrm{CI}-0.41$ to $0.84 ; \mathrm{I}^{2}=1 \%$ ) or on movement (MD $0.31 ; 95 \%$ CI -0.48 to $1.10 ; \mathrm{I}^{2}=0 \%$ ) (Fig. 2 ).

\section{Opioid consumption at $24 \mathrm{hr}$}

Opioid consumption at $24 \mathrm{hr}$ was investigated in the two studies ${ }^{15,18}$ with both reporting no difference between the two groups. No conclusion can be made on pooled results (Fig. 3) due to the wide confidence interval (MD $6.43 \mathrm{mg}$ morphine equivalents; $95 \% \mathrm{CI}-8.07$ to 20.93 ; $\mathrm{I}^{2}=98 \%$ ).

\section{Pain intensity scores at six, 12, and $48 \mathrm{hr}$}

Pain scores at six, 12, and $48 \mathrm{hr}$ at rest and on movement were reported in two, ${ }^{15,18}$ one, ${ }^{15}$ and two ${ }^{15,18}$ studies, respectively. Pooled results showed no difference between the two groups in pain scores at rest at six hours (MD -0.06; 95\% CI -0.57 to $\left.0.44 ; \mathrm{I}^{2}=0 \%\right)$, at rest at $12 \mathrm{hr}(\mathrm{MD} 0.00 ; 95 \% \mathrm{CI}-0.67$ to $0.67)$, and at rest at $48 \mathrm{hr}(\mathrm{MD} 0.28 ; 95 \% \mathrm{CI}-0.47$ to 1.03 ; $\mathrm{I}^{2}=37 \%$ ). There was a statistically significant reduction in pain scores on movement with the TAP block at six hours (MD $-0.82 ; 95 \% \mathrm{CI}-1.52$ to $-0.11 ; \mathrm{I}^{2}=0 \%$ ) but not at 12 hr (MD $0.00 ; 95 \% \mathrm{CI}-0.88$ to 0.88$)$ or at $48 \mathrm{hr}(\mathrm{MD}-0.27$; $95 \% \mathrm{CI}-1.87$ to $1.33 ; \mathrm{I}^{2}=78 \%$ ).

\section{Opioid consumption at six, 12, and $48 \mathrm{hr}$}

Opioid consumption at six, 12, and $48 \mathrm{hr}$ was investigated in the two studies. ${ }^{15,18}$ No conclusion on pooled results can be made at six hours (MD $0.48 \mathrm{mg}$ morphine equivalents; $95 \% \mathrm{CI}-3.18$ to $4.14 ; \mathrm{I}^{2}=62 \%$ ), $12 \mathrm{hr}$ (MD $2.82 \mathrm{mg}$ morphine equivalents; $95 \% \mathrm{CI}-4.81$ to $10.44 ; \mathrm{I}^{2}=92 \%$ ), or $48 \mathrm{hr}$ (MD $9.32 \mathrm{mg}$ morphine equivalents; $95 \%$ 


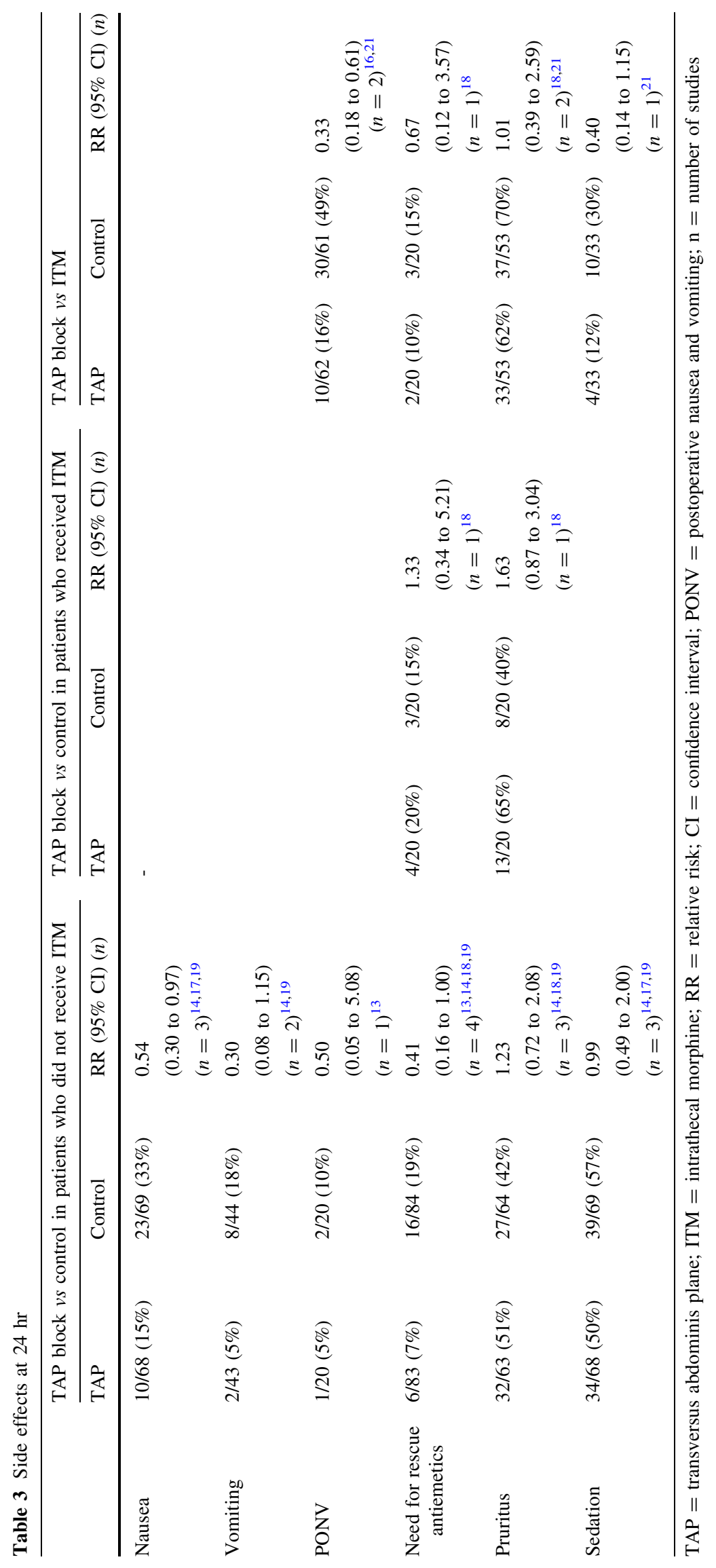


CI -10.87 to $29.50 ; \mathrm{I}^{2}=98 \%$ ) due to the wide confidence intervals.

\section{Side effects}

Side effects are presented in Table 3. One study reported a higher incidence of pruritus ${ }^{18}$ at six hours in the TAP block group (80\% with TAP block vs $45 \%$ with control; $P<0.05$ ); however, no difference was found in the incidence of pruritus at 24 or $48 \mathrm{hr}$, the need for rescue antiemetics, or sedation. ${ }^{18}$

\section{Patient satisfaction}

Patient satisfaction at $24 \mathrm{hr}$ was investigated in the two studies $^{15,18}$ with no difference between the two groups (MD $-0.14 ; 95 \% \mathrm{CI}-0.90$ to $0.62 ; \mathrm{I}^{2}=0 \%$ ).

\section{Subgroup analysis}

Comparing the two techniques of performing TAP block did not reveal a difference in pooled results between the two techniques in pain scores. There was, however, a significant difference in analgesic consumption at $24 \mathrm{hr}$ $(P<0.001)$, with lower opioid requirements in the TAP block group with the US-guided technique but higher requirements with the TAP block with the anatomical landmark technique.

\section{TAP block vs ITM}

In three studies, ${ }^{16,18,21}$ spinal anesthesia was performed using hyperbaric bupivacaine. One group received TAP block with ropivacaine or bupivacaine combined with intrathecal saline, and the other received TAP block with saline combined with ITM $100 \mu \mathrm{g}^{18,21}$ or $200 \mu \mathrm{g} .{ }^{16}$ One study ${ }^{18}$ performed TAP block using anatomical landmarks while the other two ${ }^{16,21}$ used US guidance.

\section{Pain intensity scores at $24 \mathrm{hr}$}

Pain scores at $24 \mathrm{hr}$ at rest and on movement were investigated in the three studies. ${ }^{16,18,21}$ One study ${ }^{18}$ (performed using the anatomical landmarks) reported significantly lower pain scores at rest with the use of ITM. Pooled results showed significantly lower pain scores on movement (MD 0.98; 95\% CI 0.06 to $1.91 ; \mathrm{I}^{2}=45 \%$ ) (Fig. 2) but not at rest (MD 0.60; $95 \% \mathrm{CI}-0.62$ to $1.83 ; \mathrm{I}^{2}=76 \%$ ) with ITM.

\section{Opioid consumption at $24 \mathrm{hr}$}

Opioid consumption at $24 \mathrm{hr}$ was investigated in the three studies. ${ }^{16,18,21}$ One study ${ }^{16}$ reported a lower need for rescue tramadol at $0-12 \mathrm{hr}$ in the ITM group $(P=0.03)$, while another study ${ }^{21}$ reported lower opioid consumption from $10-24 \mathrm{hr}$ in the ITM group $(P=0.003)$. Pooled results (Fig. 3) showed significantly lower opioid consumption at $24 \mathrm{hr}$ in the ITM group (MD $8.42 \mathrm{mg}$ morphine equivalents; $95 \%$ CI 1.74 to $15.10 ; \mathrm{I}^{2}=95 \%$ ).

Pain intensity scores at six, 12, and $48 \mathrm{hr}$

Pain scores at six, 12 , and $48 \mathrm{hr}$ at rest and on movement were investigated in three, ${ }^{16,18,21}$ two, ${ }^{16,21}$ and two ${ }^{16,18}$ studies, respectively. Pooled results showed no difference between the two groups in pain scores at rest at 6 hours (MD 0.82; $95 \%$ CI 0.00 to $1.64 ; \mathrm{I}^{2}=49 \%$ ), at rest at $12 \mathrm{hr}$ (MD $0.71 ; 95 \%$ CI -1.77 to $\left.3.19 ; \mathrm{I}^{2}=90 \%\right)$, and at rest at $48 \mathrm{hr}(\mathrm{MD} 0.35 ; 95 \%$ $\mathrm{CI}-0.69$ to $\left.1.38 ; \mathrm{I}^{2}=58 \%\right)$. Pain scores on movement were also not different between the two groups at six hours (MD $0.88 ; 95 \%$ CI -0.20 to $1.95 ; \mathrm{I}^{2}=54 \%$ ), at $12 \mathrm{hr}$ (MD 0.62; $95 \% \mathrm{CI}-1.73$ to $2.96 ; \mathrm{I}^{2}=89 \%$ ), and at $48 \mathrm{hr}$ (MD 0.18; $95 \%$ CI -0.61 to $\left.0.97 ; \mathrm{I}^{2}=1 \%\right)$.

\section{Opioid consumption at six, 12, and $48 \mathrm{hr}$}

Opioid consumption at six, 12, and $48 \mathrm{hr}$ was investigated in two, ${ }^{18,21}$ three, ${ }^{16,18,21}$ and two ${ }^{16,18}$ studies, respectively. Two studies ${ }^{16,18}$ reported a reduction in opioid consumption in the first 12 hours with ITM. Pooled results showed no difference between the groups at $12 \mathrm{hr}$ (MD $3.99 \mathrm{mg}$ morphine equivalents; $95 \% \mathrm{CI}-0.01$ to $7.98 ; \mathrm{I}^{2}=90 \%$ ). Due to wide confidence intervals, no conclusion can be made at six hours (MD $2.01 \mathrm{mg}$ morphine equivalents; $95 \% \mathrm{CI}-2.72$ to $6.74 ; \mathrm{I}^{2}=82 \%$ ) and at $48 \mathrm{hr}$ (MD $12.32 \mathrm{mg}$ morphine equivalents; $95 \% \mathrm{CI}-9.14$ to 33.79 ; $\left.\mathrm{I}^{2}=97 \%\right)$.

\section{Pain at three months}

The incidence of pain at three months was investigated in one study ${ }^{21}$ with no difference between the two groups (3.6\% for the TAP block group vs 3.2\% for the ITM group; $P=0.64)$.

\section{Time to first analgesic}

Time to first analgesic was investigated in one study ${ }^{16}$ with a longer mean time (standard deviation) to first analgesic with the use of ITM [4 (7.1) hr for the TAP block group $v s$ 8 (8.5) hr for the ITM group; $P=0.005]$.

\section{Side effects}

Side effects are presented in Table 3. Nausea scores were reported in one study ${ }^{16}$ with a significantly higher score 
with the use of ITM at two, four, and six hours but not at later time points. Pruritus at $48 \mathrm{hr}$ was investigated in two studies ${ }^{16,18}$ with no difference between the groups (RR $0.30 ; 95 \%$ CI 0.00 to $43.84 ; \mathrm{I}^{2}=92 \%$ ). In one study, ${ }^{16}$ pruritus scores in the ITM group were significantly higher up to $12 \mathrm{hr}$ but not at 24 or $48 \mathrm{hr}$. Sedation was investigated in three studies ${ }^{16,18,21}$ with no differences between the groups, and respiratory depression was investigated by one study ${ }^{16}$ with no reported cases.

\section{Patient satisfaction}

Patient satisfaction was investigated in two studies. ${ }^{16,18}$ In one study, ${ }^{18}$ a significantly higher VAS satisfaction score was reported with the use of ITM at six hours (MD -1.30; $95 \% \mathrm{CI}-2.53$ to -0.07$)$ but not at $24 \mathrm{hr}(\mathrm{MD}-0.75 ; 95 \%$ CI -2.23 to 0.73 ) or $48 \mathrm{hr}(\mathrm{MD}-0.60 ; 95 \% \mathrm{CI}-1.99$ to 0.79).The other study ${ }^{16}$ reported the number of patients highly satisfied, satisfied, or dissatisfied and reported no difference between the two groups.

\section{Subgroup analysis}

While both TAP block techniques were found inferior to ITM, comparing results revealed a significant difference in pain scores at rest $(P=0.008)$ and analgesic requirements at $24 \mathrm{hr}(P<0.001)$ between the two techniques in favour of the US-guided technique.

\section{Discussion}

This systematic review and meta-analysis suggests that TAP block in women who do not receive ITM might be a particularly effective modality for reducing pain scores, opioid consumption, and opiate-related side effects. In women who received ITM, TAP block had a modest effect, which was limited to reducing pain scores on movement in the early postoperative period. On the other hand, ITM produced better analgesia compared with TAP block, but it was associated with an increased incidence of opioidrelated side effects.

Pain following $\mathrm{CD}$ is multifactorial in origin with a somatic component arising from the abdominal wound and a visceral component resulting from visceral and uterine manipulation. $^{3,22}$ In patients who did not receive ITM, blocking the somatic afferents with the TAP block improved postoperative analgesia and reduced opioidrelated side effects; therefore, this technique should be recommended in patients receiving general anesthesia or in situations where long-acting neuraxial opioids are not used. However, since ITM affects both somatic and visceral afferents, ${ }^{23,24}$ postoperative analgesia was improved with ITM compared with TAP block alone; however, this was at the expense of an increased incidence of opioidrelated side effects. The role of TAP block added to ITM is less clear. While this review suggested only a modest improvement in pain scores on movement with the TAP block in the first six hours after surgery, no definitive conclusions could be obtained regarding the other outcomes. This is due to the differences in outcomes and heterogeneity of the two studies in which TAP block was added to ITM, suggesting that more studies are needed to explore whether the use of TAP block offers any benefits in patients receiving ITM.

We observed significant heterogeneity in our analysis despite the similarities in the anesthetic technique used in most of the included studies. This likely reflects the different approaches to performing the TAP block, differences in the dose and volume of local anesthetic administered, and the fact that the success of the TAP block may be operatordependent, whether performed using anatomical landmarks or under US guidance. ${ }^{17,25,26}$ With the anatomical landmark technique, the difficulty in identifying the lumbar triangle of Petit was highlighted in a study involving 26 cadaveric specimens. ${ }^{27}$ There was a marked variability in the location of the lumbar triangle of Petit, and its location was influenced by the presence of adipose tissue. Among the included studies in this review, there was a significant variation in the outcome of the two studies where the anatomical landmark technique was used. The study by McDonnell ${ }^{17}$ produced very impressive results in favour of the TAP block. This study was carried out by a group of investigators with several publications on the use of TAP block, and one experienced investigator performed all the blocks. On the other hand, McMorrow et al. ${ }^{18}$ used the same technique described by McDonnell but did not find any benefit from the use of the TAP block. The US-guided approach might offer advantages due to direct visualization of the injected local anesthetic and thus might be less operator-dependent. In fact, our subgroup analyses seemed to favour the US-guided technique. However, results from subgroup analyses may be biased and need to be interpreted with caution. ${ }^{11}$ Furthermore, groups in the study which used the anatomical landmark technique and had the least favourable outcomes with the TAP block ${ }^{18}$ were included in all three of our analyses, and as a result, they impacted the outcomes of all our subgroup analyses.

There is also some evidence suggesting that the block technique might impact the spread of local anesthetic and the resulting block. Cadaveric studies showed great variability in dye spread and level of nerve block with different TAP block approaches. ${ }^{28-30}$ For instance, the US-guided subcostal approach was associated with more dye spread and nerve involvement (T7-T12) compared with injection through the lumbar triangle of Petit or the mid-axillary approach, ${ }^{29}$ the two techniques used in the studies included 
in this review. Both the anatomical landmark and the USguided mid-axillary approaches were associated with T10L1 nerve involvement; ${ }^{29,30}$ but the anatomical landmark technique through the triangle of Petit was associated with a greater area of dye spread. ${ }^{29} \mathrm{~A}$ recent study suggested paravertebral spread of the local anesthetic as a result of injection through the triangle of petit, while the mid-axillary approach results in mainly anterior spread. ${ }^{31}$ More dye spread and nerve involvement were also reported with a TAP block technique using multiple injections compared with a technique using a single injection with a US-guided subcostal approach (T7-T12 for multiple injections vs T9T12 for single injection). ${ }^{28}$ Thus, different approaches to performing the TAP block might be associated with different levels of nerve block, therefore impacting postoperative analgesia. The doses and concentration of local anesthetic used also varied among the included studies, potentially affecting the outcome.

This systematic review has several limitations. None of the included studies tested for a sensory level resulting from the TAP block. While this was intended to maintain blinding, it did not allow for an assessment of the success rate of the TAP block. The number of studies included in this review is small, particularly those assessing the use of TAP block in patients receiving ITM and comparing TAP block with ITM; therefore, we did not assess for publication bias because tests for publication bias are not reliable in the presence of a small number of studies such as in our review. ${ }^{32-34}$ The dose of local anesthetic used also differed among the included studies, which could have contributed to the observed heterogeneity.

This systematic review identified some areas for future research. Large studies with adequate power are needed to assess the efficacy of TAP block in patients receiving ITM. These studies should also investigate whether it is possible to enhance analgesia and reduce opioid-related side effects by combining lower doses of ITM with TAP block. The impact of local anesthetic dose, concentration, or volume on the success and duration of TAP block is another area for future research. Studies are also needed to investigate the optimum TAP block approach for analgesia following $\mathrm{CD}$ as well as to examine continuous catheter techniques for TAP block. Further investigation is also needed into the effect of TAP block on the development of persistent pain in this patient population.

In conclusion, this systematic review and meta-analysis suggests that TAP block significantly improved postoperative analgesia in women undergoing $\mathrm{CD}$ who did not receive ITM, and it is therefore recommended in those patients. The value of TAP block in patients receiving ITM and its comparison with ITM remains less clear and should be investigated in future studies.
Acknowledgement Dr. George gratefully acknowledges the Canadian Anesthesiologists' Research Foundation for the 2011 CAS Career Scientist Award in Anesthesia.

Funding This article was supported solely by departmental funds.

Conflicts of interest None declared.

\section{References}

1. Pan PH. Post cesarean delivery pain management: multimodal approach. Int J Obstet Anesth 2006; 15: 185-8.

2. Kuczkowski KM. Postoperative pain control in the parturient: new challenges in the new millennium. J Matern Fetal Neonatal Med 2011; 24: 301-4.

3. McDonnell NJ, Keating ML, Muchatuta NA, Pavy TJ, Paech MJ. Analgesia after caesarean delivery. Anaesth Intensive Care 2009; 37: 539-51.

4. Gehling $M$, Tryba M. Risks and side-effects of intrathecal morphine combined with spinal anaesthesia: a meta-analysis. Anaesthesia 2009; 64: 643-51.

5. McDonnell JG, O'Donnell B, Curley G, Heffernan A, Power C, Laffey $J G$. The analgesic efficacy of transversus abdominis plane block after abdominal surgery: a prospective randomized controlled trial. Anesth Analg 2007; 104: 193-7.

6. Hebbard P, Fujiwara Y, Shibata Y, Royse C. Ultrasound-guided transversus abdominis plane (TAP) block. Anaesth Intensive Care 2007; 35: 616-7.

7. Charlton S, Cyna AM, Middleton P, Griffiths JD. Perioperative transversus abdominis plane (TAP) blocks for analgesia after abdominal surgery. Cochrane Database Syst Rev 2010; 8: CD007705.

8. Petersen PL, Mathiesen O, Torup H, Dahl JB. The transversus abdominis plane block: a valuable option for postoperative analgesia? A topical review. Acta Anaesthesiol Scand 2010; 54: 529-35.

9. Siddiqui MR, Sajid MS, Uncles DR, Cheek L, Baig MK. A metaanalysis on the clinical effectiveness of transversus abdominis plane block. J Clin Anesth 2011; 23: 7-14.

10. Liberati A, Altman DG, Tetzlaff J, et al. The PRISMA statement for reporting systematic reviews and meta-analyses of studies that evaluate health care interventions: explanation and elaboration. PLoS Med 2009; 6: e1000100.

11. Higgins J, Green S. Cochrane Handbook for Systematic Reviews of Interventions Version 5.1.0 [updated March 2011]. The Cochrance Collaboration, 2011. Available from URL: www. cochrane-handbook.org. (accessed Februrary 20, 2012).

12. Zhang J, Ho KY, Wang $Y$. Efficacy of pregabalin in acute postoperative pain: a meta-analysis. Br J Anaesth 2011; 106: 454-62.

13. Baaj JM, Alsatli RA, Majaj HA, Babay ZA, Thallaj AK. Efficacy of ultrasound-guided transversus abdominis plane (TAP) block for postcesarean section delivery analgesia-a double-blind, placebo-controlled, randomized study. Middle East J Anesthesiol 2010; 20: 821-6.

14. Belavy D, Cowlishaw PJ, Howes M, Phillips F. Ultrasound-guided transversus abdominis plane block for analgesia after caesarean delivery. Br J Anaesth 2009; 103: 726-30.

15. Costello JF, Moore AR, Wieczorek PM, Macarthur AJ, Balki M, Carvalho JC. The transversus abdominis plane block, when used as part of a multimodal regimen inclusive of intrathecal morphine, does not improve analgesia after cesarean delivery. Reg Anesth Pain Med 2009; 34: 586-9. 
16. Kanazi GE, Aouad MT, Abdallah FW, et al. The analgesic efficacy of subarachnoid morphine in comparison with ultrasoundguided transversus abdominis plane block after cesarean delivery: a randomized controlled trial. Anesth Analg 2010; 111: 475-81.

17. McDonnell JG, Curley G, Carney J, et al. The analgesic efficacy of transversus abdominis plane block after cesarean delivery: a randomized controlled trial. Anesth Analg 2008; 106: 186-91.

18. McMorrow RC, Ni Mhuircheartaigh RJ, Ahmed KA, et al. Comparison of transversus abdominis plane block vs spinal morphine for pain relief after caesarean section. Br J Anaesth 2011; 106: 706-12.

19. Tan TT, Teoh WH, Woo DC, Ocampo CE, Shah MK, Sia AT. A randomised trial of the analgesic efficacy of ultrasound-guided transversus abdominis plane block after caesarean delivery under general anaesthesia. Eur J Anaesthesiol 2012; 29: 88-94.

20. Eslamian L, Jalili Z, Jamal A, Marsoosi V, Movafegh A. Transversus abdominis plane block reduces postoperative pain intensity and analgesic consumption in elective cesarean delivery under general anesthesia. J Anesth 2012; DOI: 10.1007/s00540012-1336-3

21. Loane H, Preston R, Douglas MJ, Massey S, Papsdorf M, Tyler J. A randomized controlled trial comparing intrathecal morphine with transversus abdominis plane block for post-cesarean delivery analgesia. Int J Obstet Anesth 2012; 21: 112-8.

22. Lavand'homme $P$. Postcesarean analgesia: effective strategies and association with chronic pain. Curr Opin Anaesthesiol 2006; 19: 244-8.

23. Omote K, Kawamata M, Iwasaki H, Namiki A. Effects of morphine on neuronal and behavioural responses to visceral and somatic nociception at the level of spinal cord. Acta Anaesthesiol Scand 1994; 38: 514-7.

24. Tong C, Conklin D, Eisenach JC. A pain model after gynecologic surgery: the effect of intrathecal and systemic morphine. Anesth Analg 2006; 103: 1288-93.
25. Factor D, Chin KJ. Transversus abdominis plane block in lower segment cesarean section: a question of block failure or lack of efficacy? Reg Anesth Pain Med 2010; 35: 404-5.

26. Latzke D, Marhofer P, Kettner SC, et al. Pharmacokinetics of the local anesthetic ropivacaine after transversus abdominis plane block in healthy volunteers. Eur J Clin Pharmacol 2012; 68: 419-25.

27. Jankovic ZB, du Feu FM, McConnell P. An anatomical study of the transversus abdominis plane block: location of the lumbar triangle of Petit and adjacent nerves. Anesth Analg 2009; 109: 981-5.

28. Barrington MJ, Ivanusic JJ, Rozen WM, Hebbard P. Spread of injectate after ultrasound-guided subcostal transversus abdominis plane block: a cadaveric study. Anaesthesia 2009; 64: 745-50.

29. Milan Z, Tabor D, McConnell P, et al. Three different approaches to transversus abdominis planeblock: a cadaveric study. Med Glas Ljek komore Zenicko-doboj kantona 2011; 8: 181-4.

30. Tran TM, Ivanusic JJ, Hebbard P, Barrington MJ. Determination of spread of injectate after ultrasound-guided transversus abdominis plane block: a cadaveric study. Br J Anaesth 2009; 102: 123-7.

31. Carney J, Finnerty $O$, Rauf J, Bergin D, Laffey JG, Mc Donnell $J G$. Studies on the spread of local anaesthetic solution in transversus abdominis plane blocks. Anaesthesia 2011; 66: 1023-30.

32. Terrin N, Schmid CH, Lau J. In an empirical evaluation of the funnel plot, researchers could not visually identify publication bias. J Clin Epidemiol 2005; 58: 894-901.

33. Terrin N, Schmid CH, Lau J, Olkin I. Adjusting for publication bias in the presence of heterogeneity. Stat Med 2003; 22: 2113-26.

34. Thornton A, Lee P. Publication bias in meta-analysis: its causes and consequences. J Clin Epidemiol 2000; 53: 207-16. 